\title{
Risk of Cardiovascular Disease in First and Second Generation Mexican-Americans
}

\author{
L. S. Morales $\cdot$ M. Leng $\cdot$ J. J. Escarce
}

Published online: 24 May 2009

(C) The Author(s) 2009. This article is published with open access at Springerlink.com

\begin{abstract}
This study examines the cardiovascular disease (CVD) risk profiles of first generation (FG) and second generation (SG) Mexican-Americans (MA) in two large national studies-the Hispanic Health and Nutrition Examination Study (HHANES) (1982-1984) and the National Health and Examination Study (NHANES) (1999-2004). The main outcome measures were five individual risk indicators of CVD (total cholesterol, HDL cholesterol, hypertension, diabetes, and smoking) and a composite measure (the Framingham Risk Score [FRS]). The analyses included cross-survey (pseudocohort) and within-survey (cross-sectional) comparisons. In multivariate analyses, SG men had higher rates of hypertension and lower rates of smoking than FG men; and SG women had lower total cholesterol levels, higher rates of hypertension, and lower rates of smoking than FG women. There was no generational difference in the FRS in men or women. The cross-survey comparisons detected generational differences in CVD risk factors not detected in within-survey comparisons, particularly among MA women. Future studies of generational differences in risk should consider using pseudocohort comparisons when possible.
\end{abstract}

Keywords Mexican-American - Cardiovascular disease . Risk factors · Immigrants · Psuedo-cohort

L. S. Morales $(\varangle) \cdot$ M. Leng $\cdot$ J. J. Escarce Department of Medicine, Division of General Internal Medicine and Health Services Research, University of California Los Angeles, 911 Broxton Avenue, Los Angeles, CA 90024, USA e-mail: 1smorales@mednet.ucla.edu

\section{Introduction}

Previous research suggests that acculturation of immigrant populations to the United States is associated with worsening cardiovascular disease (CVD) risk profiles and with increasing CVD morbidity and mortality [1, 2]. Specifically, acculturation has been linked to increased body mass index [3-5], waist circumference and abdominal obesity [6, 7], hypertension [7-9], type II diabetes mellitus [10, 11], and cardiovascular morbidity and mortality [1, 12, 13]. Recent research has also shown that acculturation is associated with increasing subclinical indicators of CVD including higher levels of coronary calcification, carotid atherosclerotic plaque, and greater intima-media thickness $[14,15]$.

Research focusing on Mexican-Americans has also shown that acculturation is associated with worsening CVD risk profiles and higher CVD morbidity and mortality [16, 17]. In particular, US-born Mexican-Americans have been found to have higher levels of smoking, body mass index and obesity, hypertension, diabetes, and cholesterol than Mexican-American immigrants [6, 18]. US-born MexicanAmericans have also been shown to have higher levels of carotid atherosclerotic plaque, and greater intima-media thickness than Mexican-American immigrants [14]. In addition, research has shown that US-born Mexican Americans consume less "heart healthy diets" than Mexican immigrants [19].

One common limitation of the previous research on generational differences in CVD risk factor profiles among Mexican-Americans has been its reliance on cross-sectional data. Cross-sectional comparisons between immigrants and their US-born counterparts at a particular point in time do not provide estimates of the "true" generational effects on health because they fail to account for temporal 
trends in the health of immigrants. To estimate the "true" generational effect on health one must compare the health of parents and their children, but analyses of crosssectional surveys compare immigrants with members of the second generation in one time period. Within a crosssectional survey, members of the second generation are not the children of the immigrants; rather, they are the children of immigrants from the previous generation. If the health of immigrants has improved over time, as is likely with Mexican-American immigrants given the increases in life expectancy in Mexico over the past several decades [20], then cross-sectional studies compare today's healthier immigrants with the children of less healthy immigrants from a generation ago. Such comparisons may overstate true generational declines in health or even indicate a decline when in fact there is no change or generational progress. In research on educational outcomes, Smith [21] found that cross-sectional comparisons of immigrant and second generation Hispanics substantially understated the degree of generational progress in educational attainment and wages.

In this study, we investigate differences in CVD risk factor profiles between first and second generation Mexican-Americans with cross-sectional data from two time periods: 1982-1984 and 1999-2004. To approximate "true" comparisons between immigrants (first generation) and their children with these data, we compare immigrants in the first time period with second generation individuals in the second time period. In the social sciences, using multiple cross-sectional datasets to approximate the analysis of longitudinal data is commonly referred to as the construction of pseudo-cohorts [22]. In addition, we take the typical approach of investigating generational differences in CVD risk factor profiles between first and second generation Mexican-Americans within each cross-sectional survey.

\section{Methods}

\section{Data Sources}

This study used two data sources: (1) the Hispanic Health and Nutrition Examination Survey (HHANES), conducted between 1982 and 198 [4, 23] and (2) the 1999-2004 National Health and Nutrition Examination Survey (1999-2004 NHANES) [24]. Both data sources are general multipurpose health surveys, and public use datasets are accessible over the Internet (http://www.cdc.gov/nchs/ nhanes.htm). Both surveys used complex multistage clustered sampling designs. The HHANES sample was representative of civilian non-institutionalized MexicanAmericans living in California, Arizona, New Mexico,
Texas, and Colorado; Puerto Ricans living in the Northeast; and Cuban-Americans living in Florida at the time of the survey. The five Southwestern states included in the HHANES accounted for $83 \%$ of the Mexican-American population of the U.S. in the 1980 census [25]. The 1999-2004 NHANES sample is representative of the entire U.S. civilian non-institutionalized population, and includes oversamples of Hispanics, African-Americans, and the elderly.

Subjects in both surveys were interviewed in the household and subsequently underwent a standardized physical examination and laboratory analyses of blood and urine samples in a mobile examination center (MEC). The interviews elicited information on a wide range of health conditions, health behaviors, and demographic and socioeconomic characteristics of participants. The physical examination included measurements of height and weight as well as up to three blood pressure measurements. The laboratory tests included glucose and lipid levels. A subset of Subjects was asked to fast overnight prior to their examination and laboratory tests.

\section{Outcome Measures}

We assessed the following individual cardiovascular risk factors: hypertension (yes/no), diabetes (yes/no), total and high-density lipoprotein (HLD) cholesterol (mg/dl), current smoking status (yes/no), and body mass index (BMI) $\mathrm{kg} / \mathrm{m}$ [2] and obesity (yes/no) [26]. Subjects were categorized as having hypertension if they had a history of hypertension diagnosed by a doctor and were taking blood pressure medications, a systolic blood pressure greater than $140 \mathrm{mmHg}$, or a diastolic blood pressure greater than $90 \mathrm{mmHg}$. We used the mean of subjects' first two blood pressure measurements in determining whether they had hypertension. We used two blood pressure measurements rather than three because HHANES only has two measurements. Subjects were categorized as having diabetes if they had a history of diabetes diagnosed by a doctor and were taking medications for diabetes or had a fasting blood glucose level of $126 \mathrm{mg} / \mathrm{dl}$ or more.

In addition, we computed the Framingham Risk Score (FRS) for subjects 30-74 years of age according to the algorithms published by Wilson et al. [27]. Briefly, the FRS is a composite score that can be used to estimate the risk of developing coronary heart disease (CHD) (angina pectoris, myocardial infarction, or coronary heart disease death) over a 10-year period for adult men and women 3074 years of age. Points are assigned based on a person's age, gender, total cholesterol (mg/dl), HDL cholesterol $(\mathrm{mg} / \mathrm{dl})$, systolic and diastolic blood pressure $(\mathrm{mmHg})$, presence of diabetes (yes/no), and current smoking status (yes/no), then the points are summed to obtain the FRS. We 
assessed each subject's probability of developing CHD over a 10-year period using published tables [27].

\section{Participants}

We identified first and second generation Mexican-Americans between the ages of 20 and 74 years in the HHANES and the 1999-2004 NHANES, and excluded pregnant women. Mexican origin was based on self-report. Individuals were categorized as first generation if they were born in Mexico and second generation if they were born in the US and had at least one parent born in Mexico. In the HHANES, 2,423 first and second generation MexicanAmericans completed the interviews, 2,058 completed the interviews and the physical examination and provided blood samples, and 661 provided fasting blood samples. In the 1999-2004 NHANES, 2,296 first and second generation Mexican-Americans completed the interviews, 2,198 were examined and provided blood samples, and 951 provided fasting blood samples.

The analytic samples differed across the study outcomes depending on how the data were collected for each outcome. For example, the information on current smoking status was obtained from the interviews, the data on blood pressure measurements were obtained during the physical examination, and fasting blood glucose levels were obtained from the fasting blood samples.

\section{Statistical Analysis}

We conducted two types of statistical analyses, and stratified all analyses by gender First, we calculated the ageadjusted mean or prevalence for each individual risk factor as well as for the FRS in each of the four subgroups of subjects: Mexican immigrants in HHANES, second generation Mexican-Americans in HHANES, Mexican immigrants in the 1999-2004 NHANES, and second generation Mexican Americans in the 1999-2004 NHANES. The reference population for the age-adjustment was the U.S. population in the 2000 census. We then conducted three statistical comparisons for each outcome: (1) immigrants versus second generation within HHANES, (2) immigrants versus second generation within the 1999-2004 NHANES, and (3) immigrants in HHANES versus second generation in the 1999-2004 NHANES. The first two comparisons take the usual cross-sectional (within-survey) approach to assessing differences between first and second generation Mexican-Americans. The third comparison takes a crosssurvey approach and is intended to capture the true generational change in cardiovascular risk factors, as described earlier.
Second, we estimated multivariate regression models with the study outcomes as dependent variables. The main independent variables of interest were indicator variables for the four subgroups of subjects defined by generation (first versus second) and survey (HHNES versus 1999-2004 NHANES). The covariates in the models included indicators for age $(20-34,35-44,45-54,55-64$, 65-74), education (no high school diploma, high school diploma, or more than high school diploma, household income relative to the federal poverty level (FPL) ( $<1.0$ FPL, 1.0-2.0 FPL, 2.0-4.0 FPL), and marital status (married or living together, widowed, divorced or separated, or never married).

Several covariates had missing values including marital status ( $2 \%$ missing), education ( $8 \%$ missing), and income (7\% missing). We used modal substitution to impute missing values for marital status. Because the percent missing was somewhat higher for education and income, we used a three-step procedure to impute missing values for these variables. Each variable was imputed separately. First, we estimated an ordinal logistic regression model for each variable with sex, gender, age, martial status, and generation as independent variables. Second, for each individual with missing data we generated probability cutpoints for each category of the variable using the regression coefficients from the model. Third, we drew a random number between zero and one from a uniform distribution and compared it to the probability cut-points in order to assign each individual to one category.

To account for the complex study designs used in HHNAES and NHANES 1999-2004, all analyses were conducted in SUDAAN 8.0 using the recommended weights for each sample by NCHS [24]. This research was exempted from human subjects review by the UCLA Institutional Review Board.

\section{Results}

\section{Sample Characteristics}

Table 1 shows selected sociodemographic characteristics of first and second generation Mexican-Americans in the HHANES and the NHANES 1999-2004 examination samples. In both the HHANES and NHANES 1999-2004 approximately half of the subjects were female. In both surveys, first generation Mexican-Americans were younger, had lower levels of education, and had lower levels of income than the second generation. In both surveys, approximately three-quarters of first and second generation Mexican-Americans were married. 
Table 1 Selected characteristics of HHNANES 1982-1984 and NHNAES 1999-2004 examination samples

\begin{tabular}{|c|c|c|c|c|}
\hline & \multicolumn{2}{|c|}{ HHANES $1982-1984(n=2,058)$} & \multicolumn{2}{|c|}{ NHANES 1999-2004 $(n=2,198)$} \\
\hline & $\begin{array}{l}\text { First generation } \\
(n=1,270)\end{array}$ & $\begin{array}{l}\text { Second generation } \\
(n=788)\end{array}$ & $\begin{array}{l}\text { First generation } \\
(n=1,617)\end{array}$ & $\begin{array}{l}\text { Second generation } \\
(n=581)\end{array}$ \\
\hline \multicolumn{5}{|l|}{$N($ weighted \%) } \\
\hline \multicolumn{5}{|l|}{ Gender } \\
\hline Male & $600(55)$ & $341(49)$ & $853(58)$ & $280(49)$ \\
\hline Female & $670(45)$ & $447(51)$ & $764(42)$ & $301(51)$ \\
\hline \multicolumn{5}{|l|}{ Age (Years) } \\
\hline $20-34$ & $558(53)$ & $247(39)$ & $550(50)$ & $158(49)$ \\
\hline $35-44$ & $251(21)$ & $123(19)$ & $377(27)$ & $76(20)$ \\
\hline $45-54$ & $230(12)$ & $206(19)$ & $246(13)$ & $69(14)$ \\
\hline $55-74$ & $231(14)$ & $212(23)$ & $444(10)$ & $278(17)$ \\
\hline \multicolumn{5}{|l|}{ Marital status } \\
\hline Married/living with partner & $975(75)$ & $575(73)$ & $1178(73)$ & $415(64)$ \\
\hline Widowed & $51(3)$ & $40(4)$ & $86(2)$ & $27(2)$ \\
\hline Divorced or separated & $101(7)$ & $88(11)$ & $126(6)$ & $56(9)$ \\
\hline Never married & $143(14)$ & $85(13)$ & $227(19)$ & $83(25)$ \\
\hline \multicolumn{5}{|l|}{ Education } \\
\hline Less than high school diploma & $1037(80)$ & $439(51)$ & $1222(70)$ & $259(32)$ \\
\hline High school diploma & $147(13)$ & $194(26)$ & $200(16)$ & $124(27)$ \\
\hline More than high school & $86(8)$ & $155(23)$ & $195(14)$ & $198(41)$ \\
\hline \multicolumn{5}{|l|}{ Family income (PIR) } \\
\hline$<1.00$ & $431(33)$ & 199 (24) & $538(33)$ & $106(19)$ \\
\hline $1.00-2.00$ & $523(42)$ & $260(33)$ & $656(41)$ & $171(28)$ \\
\hline $2.00-4.00$ & $275(22)$ & $232(30)$ & $325(21)$ & $196(35)$ \\
\hline$>4.00$ & $41(4)$ & $97(13)$ & $98(6)$ & $108(18)$ \\
\hline
\end{tabular}

Age-adjusted Results

Table 2 shows the age-adjusted cross-survey and withinsurvey comparisons between first and second generation Mexican-American men and women. Among men, there were no differences between first and second generation men in FRS, total cholesterol or diabetes rates by either the cross-survey or cross-sectional methods of analysis. In both the cross-survey and HHANES within-survey comparisons, second generation men were less likely to smoke than first generation men. In the cross-survey comparison, second generation men had lower HDL cholesterol than first generation men. In the HHANES within-survey comparison, second generation men had higher rates of hypertension than first generation men (HHANES).

Among women, there were no differences in FRS or diabetes rates between the first and second generations by either the cross-survey or within-survey comparisons. By both methods of comparison, second generation women had higher HDL cholesterol than first generation women. In the cross-survey comparison only, second generation women had lower total cholesterol, higher rates of hypertension, and lower rates of smoking compared to the first generation counterparts.

\section{Multivariate Results}

Table 3 shows the cross-survey and within-survey multivariate regression comparisons in cardiovascular risk between first and second generation men and women controlling for age, marital status, education, and income. Results from the multivariate comparisons were largely consistent with the age-adjusted results, with the following caveats. Among men, multivariate adjustment rendered the cross-survey comparison in the HDL cholesterol non-significant; the cross-survey and within-survey (NHANES 1999-2004) HTN comparisons significant where they had been non-significant in the age-adjusted results; and the within-survey (NHANES 1999-2004) comparison of smoking non-significant. Among women, multivariate adjustment rendered both cross-survey comparisons and the within-survey comparisons in HDL cholesterol nonsignificant. 
Table 2 Age-adjusted cross-survey and within-survey comparisons in cardiovascular risk first and second generation Mexican-American men and women

\begin{tabular}{|c|c|c|c|c|c|c|}
\hline & $\begin{array}{l}10 \text {-year risk of cardiovascular } \\
\text { event }(\%[95 \% \mathrm{CI}])\end{array}$ & $\begin{array}{l}\text { Cholesterol } \\
(\mathrm{mg} / \mathrm{dl}[\mathrm{SE}])\end{array}$ & $\begin{array}{l}\text { HDL Cholesterol } \\
(\mathrm{mg} / \mathrm{dl}[\mathrm{SE}])\end{array}$ & $\begin{array}{l}\text { HTN } \\
(\%[95 \% \mathrm{CI}])\end{array}$ & $\begin{array}{l}\text { Diabetes } \\
(\%[95 \% \mathrm{CI}])\end{array}$ & $\begin{array}{l}\text { Current smokers } \\
(\%[95 \% \mathrm{CI}])\end{array}$ \\
\hline \multicolumn{7}{|l|}{ Men } \\
\hline HHANES-I ${ }^{\mathrm{a}}$ & $11(10,12)$ & $206.95(1.12)$ & $47.38(0.60)^{1}$ & $19(16,24)^{2}$ & $8(5,14)$ & $44(41,48)^{1,2}$ \\
\hline HHANES-II $^{\mathrm{b}}$ & $11(10,12)$ & $208.87(2.15)$ & $47.46(0.99)$ & $30(25,35)^{2}$ & $9(6,16)$ & $38(34,44)^{2}$ \\
\hline NHANES-I ${ }^{\mathrm{c}}$ & $10(9,11)$ & $205.69(1.47)$ & $45.54(0.51)$ & $20(17,23)$ & $9(6,12)$ & $29(26,32)$ \\
\hline NHANES-II $^{\mathrm{d}}$ & $11(10,12)$ & $208.10(3.51)$ & $45.32(0.97)^{1}$ & $27(20,34)$ & $14(20,32)$ & $26(20,32)^{1}$ \\
\hline \multicolumn{7}{|l|}{ Women } \\
\hline HHANES-I & $5(5,6)$ & $207.04(1.70)^{1}$ & $50.70(0.92)^{1,2}$ & $20(17,23)^{1}$ & $6(3,11)$ & $22(19,24)^{1}$ \\
\hline HHANES-II & $5(4,5)$ & $210.53(2.62)$ & $53.10(0.88)^{2}$ & $22(19,25)$ & $6(2,16)$ & $23(19,28)$ \\
\hline NHANES-I & $5(5,6)$ & 196.08 (1.63) & $51.88(0.56)^{3}$ & $23(20,25)$ & $14(10,20)$ & $12(9,14)$ \\
\hline NHANES-II & $5(5,6)$ & $197.42(2.35)^{1}$ & $54.63(0.85)^{1,3}$ & $30(23,38)^{1}$ & $9(5,16)$ & $10(6,14)^{1}$ \\
\hline
\end{tabular}

Note: The reference population for age-adjustment was the 2000 census U.S. population

a HHANES-I refers to first generation HHANES

b HHANES-II refers to second generation HHANES

c NHANES-I refers to first generation NHANES 1999-2004

d NHANES-II refers to second generation NHANES 1999-2004

${ }^{1}$ Cross-survey comparison significant at the $P<0.05$ level (HHANES first generation versus NHANES 1999-2004 second generation)

${ }^{2}$ Within-survey comparison significant at the $P<0.05$ level (HHANES first generation versus HHANES second generation)

${ }^{3}$ Within-survey comparison significant at the $P<0.05$ level (NHANES 1999-2004 first generation versus NHANES 1999-2004 second generation)

\section{Within-Survey Versus Cross-survey Analyses}

There were some noteworthy differences between the results obtained by the cross-survey and within-survey methods of analysis, particularly in women. Application of the withinsurvey approach only identified a difference in HDL cholesterol between first and second generation women. In contrast, application of the cross-survey approach identified differences in total cholesterol, hypertension, and smoking between first and second generation women. These findings suggest that it is important to consider temporal trends in the health of immigrants when evaluating generational differences.

\section{Discussion}

Whether first and second generation Mexican-Americans were compared using the cross-survey approach (HHANES first generation versus NHANES 1999-2004 second generation) or the within-survey approach (HHANES first versus second generation and NHANES 1999-2004 first versus second generation), significant generational differences in individual cardiovascular disease risk factors levels were found. Specifically, second generation men had a higher rate of hypertension than first generation men in the cross-survey comparison and in both within-survey comparisons; second generation women had a higher hypertension rate than first generation women, but only in the cross-survey comparison; second generation men and women had lower smoking rates in the cross-survey comparisons and in men, in the within-survey comparison using HHANES only; second generation men had a lower mean HDL cholesterol level in the cross-survey comparison whereas second generation women had a higher mean HDL level in the cross-survey comparison and both within-survey comparisons; and lastly, second generation women had a lower mean total cholesterol level in the cross-survey comparison.

As discussed in the Introduction, most previous studies of generational differences in cardiovascular disease risk factors in Hispanics relied on cross-sectional (within-survey) comparisons. However, generational differences found in cross-sectional data may be confounded by secular trends in the health of immigrants. The optimal way to investigate generational differences in risk factor levels would be to use multigenerational longitudinal data that includes immigrants and their children. Unfortunately, these kinds of longitudinal studies of Mexican immigrants and their children are not currently available. In this study, we have addressed this issue by comparing first generation adults in an older data set (HHANES) with second generation adults in a newer data set (NHANES), approximating comparisons between immigrant parents and their US-born children (i.e., cross-survey 
Table 3 Multivariate adjusted cross-survey and within-survey comparisons in cardiovascular risk in first and second generation MexicanAmerican men and women

\begin{tabular}{|c|c|c|c|c|c|c|}
\hline & $\begin{array}{l}\text { 10-year risk of } \\
\text { cardiovascular event } \\
\text { (Adjusted \%) }\end{array}$ & $\begin{array}{l}\text { Total cholesterol } \\
\text { (Adjusted level } \\
{[\mathrm{mg} / \mathrm{dl}] \text { ) }}\end{array}$ & $\begin{array}{l}\text { HDL cholesterol } \\
\text { (Adjusted level } \\
{[\mathrm{mg} / \mathrm{dl}] \text { ) }}\end{array}$ & $\begin{array}{l}\text { HTN } \\
\text { (Adjusted \%) }\end{array}$ & $\begin{array}{l}\text { Diabetes } \\
\text { (Adjusted \%) }\end{array}$ & $\begin{array}{l}\text { Current smokers } \\
\text { (Adjusted \%) }\end{array}$ \\
\hline \multicolumn{7}{|l|}{ Men } \\
\hline HHANES-I ${ }^{\mathrm{a}}$ & 7 & 200.91 & 47.12 & $15^{1,2}$ & 6 & $43^{1}$ \\
\hline HHANES-II $^{\mathrm{b}}$ & 8 & 204.47 & 47.62 & $22^{2}$ & 6 & 44 \\
\hline NHANESIV-I ${ }^{\mathrm{c}}$ & 6 & 202.01 & 45.41 & $13^{3}$ & 6 & 29 \\
\hline NHANESIV-II ${ }^{\mathrm{d}}$ & 7 & 202.19 & 45.59 & $20^{1,3}$ & 8 & $32^{1}$ \\
\hline \multicolumn{7}{|l|}{ Women } \\
\hline HHANES-I & 3 & $201.43^{1}$ & 51.26 & $14^{1}$ & 4 & $21^{1}$ \\
\hline HHANES-II & 3 & 202.44 & 52.34 & 16 & 5 & 23 \\
\hline NHANESIV-I & 3 & 191.76 & 51.81 & 16 & 9 & 12 \\
\hline NHANESIV-II & 4 & $189.13^{1}$ & 52.51 & $23^{1}$ & 8 & $8^{1}$ \\
\hline
\end{tabular}

Note: Results adjusted for age, sex, marital status, education, and income

${ }^{a}$ HHANES-I refers to first generation HHANES

b HHANES-II refers to second generation HHANES

c NHANES-I refers to first generation NHANES 1999-2004

d NHANES-II refers to second generation NHANES 1999-2004

${ }^{1}$ Cross-survey comparison significant at the $P<0.05$ level (HHANES first generation versus NHANES 1999-2004 second generation)

2 Within-survey comparison significant at the $P<0.05$ level (HHANES first generation versus HHANES second generation)

${ }^{3}$ Within-survey comparison significant at the $P<0.05$ level (NHANES 1999-2004 first generation versus NHANES 1999-2004 second generation)

approach). In the social sciences, the technique of approximating longitudinal data by using multiple waves of crosssectional data is referred to as the pseudo-cohort approach [22]. Our results suggest that indeed there are important differences between the results obtained from cross-survey (cross-survey) and cross-sectional (within-survey) comparisons; in the case of this study, particularly among women. Specifically, first and second generation women differed with respect to total cholesterol, hypertension and smoking in the cross-survey comparisons but not cross-sectional comparisons. Researchers using cross-sectional data to investigate generational differences in health should be aware of the potential for confounding due to secular trends in the health of immigrants and seek to check their results using pseudo-cohorts when feasible.

Despite there being differences in individual risk factor levels, first and second generation Mexican-Americans had similar overall risks of developing coronary heart disease over a ten-year time horizon. Specifically, first and second generation men and women had statistically similar 10 -year risk of coronary heart disease as estimated by the FRS, whether immigrant men and women were compared with their second generation counterparts using cross-survey or within-survey comparisons. These results suggest that the risk factor distributions favoring one generation may have been balanced by those favoring the other, resulting in no net difference in near-term cardiovascular risk. For example, compared to first generation women, second generation women had higher hypertension rates but also lower smoking rate rates. Another possible explanation for the lack of any significant generational differences in the FRS may have been the small numbers of older first and second generation Mexican-Americans in HHANES. In HHANES, there were only 61 men and 75 women that were 65 years of age and older. Had there been greater numbers of older Mexican-American men and women in these studies, significant generational differences in risk might have been detectable.

In contrast to this study, previous studies have found that less acculturated Hispanics have more favorable cardiovascular disease risk factor profiles than more acculturated Hispanics. For example, compared with US-born Hispanics, foreign-born Hispanics have been found to have more favorable levels of blood pressure, cholesterol, diabetes, body mass index, abdominal circumference, smoking, and coronary calcifications [6, 12, 15, 28]. There are, however, important methodological differences between this and previous studies. First, previous studies have frequently compared foreign-born Hispanics to US-born Hispanics, not distinguishing among the multiple generations of US-born Hispanics. If acculturation continues across multiple generations as suggested by Portes and Rumbaut [29], then important differences between second, third, fourth, and higher generations of Mexican-Americans 
may be unaccounted for in earlier studies. In contrast, this study was limited to comparisons between first and second generation individuals. Second, many previous studies pool Hispanics together regardless of ethnic or national background. There is, however, mounting evidence that Hispanic subgroups differ with respect to risk factors, mortality and many other important measures of health status [30]. To avoid the possible confounding of generational differences by compositional differences in national origin, this study is limited to Mexican-Americans. Finally, generational status is not a measure for acculturation, though the two measures are correlated. Generational status is solely determined by the birthplaces of an individual and of her parents. By contrast, acculturation is a multidimensional construct that is defined by factors such as engaging in culturally-specific behaviors (e.g., food, music and media); language proficiency; knowledge of culturespecific history and current events; the cultural makeup of one's social network; and one's own ethnic and cultural identity [31]. Thus studies that have used measures of acculturation may not find the same results as this study that used generation.

Access to care could have confounded the results of this study, particularly with respect to cholesterol levels. Conceptually, access to care might influence cholesterol levels by leading to the receipt of cholesterol lowering drugs. Thus individuals with better access to care might have lower cholesterol levels independent of their generational status. Unfortunately, HHANES does not include variables that allow us to evaluate the prevalence of dyslipidemias (as opposed to cholesterol level). To better understand the relationship between cholesterol levels and access to care, we regressed cholesterol on generational status, age, and usual source of care (yes/no). Among women, controlling for usual source of care made no difference in the results. Among men, however, controlling for usual source of care resulted in the contrast between first and second generation within HHANES becoming insignificant. Interestingly, men with a usual source of care had higher cholesterol levels (beta $=6.02 ; P=0.05$ ) than men without a usual source of care, suggesting that need for care (as measured by cholesterol) was associated with access to care (as measured by usual source of care). The impact of the risk factors in this study on future cardiovascular morbidity and mortality will depend upon access to health care and to appropriate risk reducing therapies.

Mexican-Americans are the largest and fastest growing subgroup of Hispanics in the US, yet despite their demographic importance Mexican-American immigrants and their children remain vastly understudied groups. Because of their increasing numbers, Mexican-American immigrants and their children are destined to have significant impacts on the US health care system. Therefore gaining a better understanding of generational changes in health and factors that influence generational changes in health among Mexican-Americans is essential. This research study takes a small step towards developing a better understanding of the role of generational change and health. However, much more population-based research targeting Mexican-American immigrants is needed before effective interventions to maintain and improve health in these groups can be developed.

Acknowledgements This research was supported by a grant from the Russell Sage Foundation. In addition, Dr. Morales received support from the Resource Center for Minority Aging Research at UCLA under Grant P30-AG02168 and the DREW-UCLA Project Export at UCLA under grant P20-MD000182.

Open Access This article is distributed under the terms of the Creative Commons Attribution Noncommercial License which permits any noncommercial use, distribution, and reproduction in any medium, provided the original author(s) and source are credited.

\section{References}

1. Robertson TL, Kato H, Gordon T, Kagan A, Rhoads GG, Land $\mathrm{CE}$, et al. Epidemiologic studies of coronary heart disease and stroke in Japanese men living in Japan, Hawaii and California. Coronary heart disease risk factors in Japan and Hawaii. Am J Cardiol. 1977;39(2):244-9. doi:10.1016/S0002-9149(77)80198-7.

2. Marmot MG, Syme SL. Acculturation and coronary heart disease in Japanese-Americans. Am J Epidemiol. 1976;104(3):225-47.

3. Gordon-Larsen P, Harris KM, Ward DS, Popkin BM. National longitudinal study of adolescent health: acculturation and overweight-related behaviors among Hispanic immigrants to the US: the national longitudinal study of adolescent health. Soc Sci Med. 2003;57(11):2023-34. doi:10.1016/S0277-9536(03)00072-8.

4. Popkin BM, Udry JR. Adolescent obesity increases significantly in second and third generation U.S. immigrants: the national longitudinal study of adolescent health. J Nutr. 1998;128(4):701-6.

5. Lauderdale DS, Rathouz PJ. Body mass index in a US national sample of Asian Americans: effects of nativity, years since immigration and socioeconomic status. Int $\mathrm{J}$ Obes Relat Metab Disord. 2000;24(9):1188-94. Erratum in: Int J Obes Relat Metab Disord 2002;26(11):1521. doi:10.1038/sj.ijo.0801365.

6. Sundquist J, Winkleby M. Country of birth, acculturation status and abdominal obesity in a national sample of Mexican-American women and men. Int J Epidemiol. 2000;29(3):470-7. doi: 10.1093/ije/29.3.470.

7. Kaufman JS, Durazo-Arvizu RA, Rotimi CN, McGee L, Cooper RS. Obesity and hypertension prevalence in populations of African origin. The investigators of the international collaborative study on hypertension in Blacks. Epidemiol (Cambridge, Mass.). 1996;7(4):398-405. doi:10.1097/00001648-19960700000010 .

8. Goslar PW, Macera CA, Castellanos LG, Hussey JR, Sy FS, Sharpe PA. Blood pressure in Hispanic women: the role of diet, acculturation, and physical activity. Ethn Dis. 1997;7(2):106-13.

9. Espino DV, Maldonado D. Hypertension and acculturation in elderly Mexican Americans: results from 1982-84 Hispanic HANES. J Gerontol. 1990;45(6):M209-13.

10. West SK, Munoz B, Klein R, Broman AT, Sanchez R, Rodriguez $\mathrm{J}$, et al. Risk factors for Type II diabetes and diabetic retinopathy in a Mexican-American population: Proyecto VER. Am J 
Ophthalmol. 2002;134(3):390-8. doi:10.1016/S0002-9394(02)015 95-7.

11. Cooper RS, Rotimi CN, Kaufman JS, Owoaje EE, Fraser H, Forrester T, et al. Prevalence of NIDDM among populations of the African diaspora. Diabetes Care. 1997;20(3):343-8. doi: 10.2337/diacare.20.3.343.

12. Sundquist J, Winkleby MA. Cardiovascular risk factors in Mexican American adults: a transcultural analysis of NHANES III, 1988-1994. Am J Public Health. 1999;89(5):723-30. doi: 10.2105/AJPH.89.5.723.

13. Fang J, Madhavan S, Alderman MH. The association between birthplace and mortality from cardiovascular causes among black and white residents of New York City. N Engl J Med. 1996; 335(21):1545-51. doi:10.1056/NEJM199611213352101.

14. Lutsey PL, Diez Roux AV, Jacobs DR Jr, Burke GL, Harman J, Shea S, et al. Associations of acculturation and socioeconomic status with subclinical cardiovascular disease in the multi-ethnic study of atherosclerosis. Am J Public Health. 2008;98(11): 1963-70. doi:10.2105/AJPH.2007.123844.

15. Diez Roux AV, Detrano R, Jackson S, Jacobs DR Jr, Schreiner PJ, Shea $\mathrm{S}$, et al. Acculturation and socioeconomic position as predictors of coronary calcification in a multiethnic sample. Circulation. 2005;112(11):1557-65. doi:10.1161/CIRCULATIONAHA. 104.530147.

16. Abraído-Lanza AF, Dohrenwend BP, Ng-Mak DS, Turner JB. The Latino mortality paradox: a test of the "salmon bias" and healthy migrant hypotheses. Am J Public Health. 1999; 89(10):1543-8. doi:10.2105/AJPH.89.10.1543.

17. Stern MP, Wei M. Do Mexican Americans really have low rates of cardiovascular disease? Prev Med. 1999;29(6 Pt 2):S90-5. doi: 10.1006/pmed.1998.0464.

18. Singh GK, Siapush M. All-cause and cause-specific mortality of immigrants and native born in the United States. Am J Public Health. 2001;91:392-9. doi:10.2105/AJPH.91.3.392.

19. Dixon LB, Sundquist J, Winkleby M. Differences in energy, nutrient, and food intakes in a US sample of Mexican-American women and men: findings from the third national health and nutrition examination survey, 1988-1994. Am J Epidemiol. 2000;152(6):548-57. doi:10.1093/aje/152.6.548.

20. Frenk J, González-Pier E, Gómez-Dantés O, Lezana MA, Knaul FM. Comprehensive reform to improve health system performance in Mexico. Lancet. 2006;368(9546):1524-34. doi: 10.1016/S0140-6736(06)69564-0.

21. Smith JP. Assimilation across the Latino generations. Am Econ Rev. 2003;93(2):315-9. doi:10.1257/000282803321947263.

22. Victor C. The social context of ageing. A textbook of gerontology. New York: Routledge; 2004.

23. National Center for Health Statistics (NCHS). Plan and operation of the Hispanic health and nutrition examination survey 19821984. Vital Health Stat [1]. 1985; No. 19. DHHS Publication PHS 85-1321.

24. Centers for Disease Control and Prevention (CDC). National Center for Health Statistics (NCHS). National health and nutrition examination survey data. Hyattsville, MD: U.S. Department of Health and Human Services, Centers for Disease Control and Prevention. 2008. http://www.cdc.gov/nchs/nhanes.htm.

25. U.S. Bureau of the Census. 1980 census of population. Supplementary report, persons of Spanish origin by state: 1980, PC80S1-10. Washington, DC: U.S. Government Printing Office; 1983.

26. Pi-Sunyer FX. Medical hazards of obesity. Ann Intern Med. 1993;119(7):655-60.

27. Wilson PW, D'Agostino RB, Levy D, Belanger AM, Silbershatz $\mathrm{H}$, Kannel WB. Prediction of coronary heart disease using risk factor categories. Circulation. 1998;97(18):1837-47.

28. Otero-Sabogal R, Sabogal F, Pérez-Stable EJ, Hiatt RA. Dietary practices, alcohol consumption, and smoking behavior: ethnic, sex, and acculturation differences. J Nat Cancer Ins Monogr. 1995(18):73-82.

29. Portes A, Rumbaut RG. Immigrant America: a portrait. Berkley and Los Angeles, California: The University of California Press; 1996.

30. National Research Council. Hispanics and the future of America. Panel on Hispanics in the United States. In: Tienda M, Mitchell F, editors. Committee on population, division of behavioral and social sciences and education. Washington DC: The National Academies Press; 2006.

31. Lara M, Gamboa C, Kahramanian MI, Morales LS, Bautista DE. Acculturation and Latino health in the United States: a review of the literature and its sociopolitical context. Annu Rev Public Health. 2005;26:367-97. doi:10.1146/annurev.publhealth.26. 021304.144615 . 